\title{
Effect of Climatic Variability on the Fishery of Indian Oil Sardine Along Kerala Coast
}

\author{
Valiyakath Hussain Sajna', Pariappanal Ulahannan Zacharia ${ }^{+*}$, Vazhamattom Benjamin Liya ${ }^{\dagger}$, \\ Girindran Rojith ${ }^{\dagger}$ Kuriakose Somy ${ }^{\dagger}$, Dhanya Joseph", and George Grinson ${ }^{\dagger}$ \\ ${ }^{\dagger}$ ICAR-Central Marine Fisheries \\ Research Institute, Kochi, Kerala, India
}
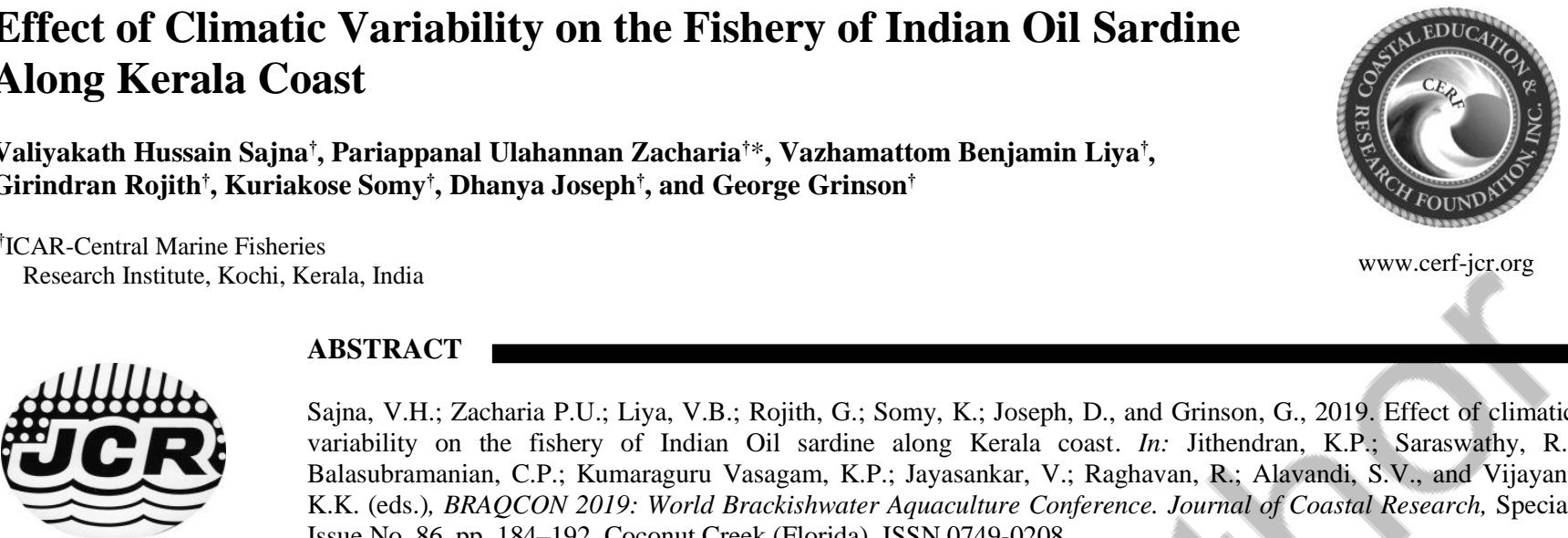

\begin{abstract}
Sajna, V.H.; Zacharia P.U.; Liya, V.B.; Rojith, G.; Somy, K.; Joseph, D., and Grinson, G., 2019. Effect of climatic variability on the fishery of Indian Oil sardine along Kerala coast. In: Jithendran, K.P.; Saraswathy, R.; Balasubramanian, C.P.; Kumaraguru Vasagam, K.P.; Jayasankar, V.; Raghavan, R.; Alavandi, S.V., and Vijayan, K.K. (eds.), BRAQCON 2019: World Brackishwater Aquaculture Conference. Journal of Coastal Research, Special Issue No. 86, pp. 184-192. Coconut Creek (Florida), ISSN 0749-0208.
\end{abstract}

www.JCRonline.org

Indian oil sardine (IOS), the commercially and ecologically important pelagic fish of the Kerala coast is susceptible to climatic variation. The study analyzes the impact of climate change on the catch of Sardinella longiceps along the Kerala coast and tries to predict the catch trend under the two RCP scenarios 4.5 and 6.0 for the period 2020-2100. Monthly catch of IOS by major gears for the period 1990-2016 was collected and Relative effort (Effort) and Weighted CPUE (срие) were accordingly estimated. The climatic variables Sea Surface Temperature (SST), Precipitation (Pr), Chlorophyll $a$ (SSC) and Salinity (SSS) were obtained from NOAA/NASA. The relationship of cpue and Effort of IOS to environmental variables were explored by Generalized Additive Model. The best fit model was selected using lowest Akaike information criterion (AIC) value, Deviance and F statistic. Predictions of cpue and Effort under RCP 4.5 and RCP 6.0 were done and the catch of IOS was estimated. The GAM model revealed the variations in the catch of IOS in relation to climate change. The SST, SSS and Pr showed a negative relation whereas SSC was found to be positively related to the catch of IOS. The results of the study indicate a decreasing trend of сриe and catch and an increasing trend of Effort towards 2100 under both climate change scenarios.

ADDITIONAL INDEX WORDS: Climate change, CPUE, generalized additive model, Indian oil sardine, Kerala coast, $R C P$.

\section{INTRODUCTION}

The climate of our planet is changing and the effects can be seen as global temperature rising, weather getting more extreme, sea levels rising, the oceans becoming more acidic and nutrient loads changing (Brierley and Kingsford, 2009). Increasing frequency and intensity of extreme climate events are likely to have a major impact on the marine environment and indirectly on fisheries (Brander, 2007). Fish species with rapid turnover of generations may show the most demographic responses to these changes (Perry et al., 2005). Fishing shows different trends in response to changes that affect larval stages, reproduction, feeding and migration, as well as anthropic pressures. Possible environmental changes, such as the increased SST, precipitation, chlorophyll concentration and salinity, surge intensity and nutrient concentration mechanisms and can affect the food chain and therefore the abundance, distribution and availability of fish populations (Miller and Schneider, 2000). Tropical species are considered to be especially sensitive to climate change because they live close to their thermal maximum and exhibit limited capacity for acclimation (Stillman, 2003)

India is the second largest producer of fish in the world, contributing about 5.43 percent of the world production.

DOI: 10.2112/ SI86-028.1 received 6 March 2019; accepted in revision 14 May 2019.

*Corresponding author: zachariapu@yahoo.com

${ }^{\oplus}$ Coastal Education and Research Foundation, Inc. 2019
The Indian marine fisheries sector thus plays a strategic role in food security, international trade and employment generation in the country (Shyam, Rahman, and Antony, 2015). Among the commercially important marine fish species harvested in India, IOS occupies the foremost position along with mackerel in terms of landings and consumption. Kerala contributes a great magnitude (up to 65\%) to the total IOS catch of the country (Shyam, Rahman, and Antony, 2015). Purse seiners, ring seiners (major catch) and the trawlers (by catch) constitute major fishing gears in the region, and are operated actively in locations where the oil sardine schools aggregate. Sardinella longiceps or Indian oil sardine (IOS) is one of the key forage organism for marine predators, including fish, squid, marine mammals, and seabirds. They are of increasing interest for conservation because of their perceived role as critical forage for charismatic mega fauna (e.g., marine mammals and seabirds) in many regions, and are often in the public eye (Cury et al., 2011). The spawning period, (Antony Raja, 1969) feeding habits (Remya and Vivekanandan, 2013) and fishery of IOS is directly and indirectly subjective to changes in climate (Krishnakumar and Bhat, 2008; Kumar et al., 2009). Since the variations in pelagic resources particularly sardine and anchovies are closely linked to the environmental changes on different time and spatial scales, realistic models of these fish populations with climate change and fishing at appropriate scale and resolution are achievable. The interactions between fish and their environment 
can now be examined by incorporating a wide range of remote sensing oceanographic variables into fishery data which can contribute largely to the management of fisheries. Given the importance of pelagic fishing in the Kerala coast, this study analyses a GAM model of IOS and climatic variables, and predicts catch potential up to 2100 under two RCP scenarios 4.5 and 6.0 respectively. This multivariate approach considers the quarterly catches of IOS, local and global environmental variables and fishing effort for the period 1985-2016.

\section{METHODS}

Study area was selected. Data on climatic variables and fishery of IOS for the study area were collected. The data was standardized and model fitting and prediction was done using $\mathrm{R}$ software.

\section{Study Area}

The peculiar feature of marine environment in the Kerala coast is the coastal upwelling and the mud banks especially in the Malabar coast. Climate driven monsoon upwelling with subsequent replenishment of nutrients to the surface waters affect plankton blooms leading to a better fishery. Thus Malabar Coast rich in primary and secondary production, contributes nearly $50 \%$ of the total Indian marine fish landings (Smith and Madhupratap, 2005; Vivekanandan et al., 2003). Most stocks of IOS by purse seine and ring seine fisheries in the Western Arabian Sea are distributed in the upwelling region along the Kerala coast (Figure 1). The study area comprises the Kerala coast region between $8^{\circ} \mathrm{N}$ and $12^{\circ} \mathrm{N}$ latitudes and $75^{\circ} \mathrm{E}$ and $77^{\circ}$ E longitudes.

\section{Environmental Data}

Environmental variables, such as sea surface temperature (SST), sea surface chlorophyll- $a$ concentration (SSC), sea surface salinity (SSS) and precipitation (Pr) related to the distribution of IOS were used in the current investigation. To analyze the temporal changes in the climatic and oceanographic variables off Kerala, monthly average data on these variables were downloaded for $8^{\circ}$ and $12^{\circ} \mathrm{N}$ latitudes and $75^{\circ}$ and $77^{\circ} \mathrm{E}$ longitudes for the historic period. From this data set the quarterly data for the period 1998-2016 were averaged. The SST data was downloaded from, International Comprehensive Ocean-Atmosphere Data Set (ICOADS - NOAA, http:// www.icoads.noaa.gov), precipitation (Pr) data was obtained from CPC Merged Analysis of Precipitation dataset (COARDSNOAA, http://www.esrl.noaa.gov). The remote sensing data were aggregated by month in $1^{\circ}-$ by- $1^{\circ}$ square grid cells. Non log-transformed chlorophyll $a$ (SSC) data from OCI (SeaDASNASA, http://www.seadas.gsfc.nasa.gov) for $4 \mathrm{~km}$ resolution and salinity (SSS) from MIROC-ESM-CHEM model output prepared for CMIP5 historical (http://www.cmip.llnl.gov) were obtained.

Two climate change scenarios, as recommended in the IPCC 2014, RCP 4.5 and RCP 6.0 were selected to represent the possible scenarios with the low and high greenhouse gas emissions. Simulation data for these were collected from the CMIP5 climate model from NOAA Geophysical Fluid Dynamics Laboratory (http:// www.gfdl.noaa.gov).

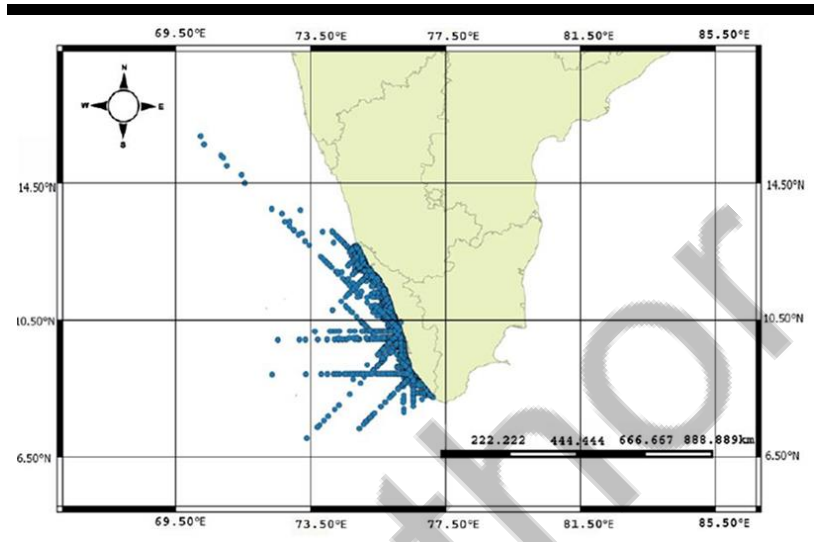

Figure 1. Fishing ground of Ring sienes along Kerala coast in the year 2015 (Figure courtesy Rohit et al., 2018).

\section{Fishery Data}

Quarterly catch data of IOS along the Kerala coast was obtained from CMFRI catch log database for the period 19852016. The dataset included information regarding fishing date, catch, and fishing effort (actual fishing hours). The catch data was standardized using the standard methodology of FAO (Gulland, 1969). The Weighted catch per unit effort (cpue or R) was calculated using yield of individual gears $(Y i)$, sum of the yields of gears for which effort is known $(Y S)$ and relative CPUE of individual gears $(R i)$. The Relative effort (Effort or $E$ ) was then calculated using $Y S$ and cpue. The calculation of cpue and Effort can be written as:

$$
\operatorname{CPUEi}(y)=\frac{Y i(y)}{f i(y)}
$$

Where, $Y i$ is the Total catch, $f i$ the effort and CPUEi the catch per unit effort of gear $i$ for the quarter $y$. Mean $C P U E i$ was calculated using the equation $\mathrm{n} 2$, where $\overline{\operatorname{CPUEi}}(y 1, y 2)$ is the mean for the time period over $\mathrm{y} 1, \mathrm{y} 1+1, \ldots \mathrm{y} 2$.

$$
\overline{\operatorname{CPUEi}}(y 1, y 2)=\frac{1}{y 2-y 1} * \sum_{j=y 1}^{y 2} \operatorname{CPUEi}(\mathrm{j})
$$

The relative CPUE (Ri) of each quarter $y$ for individual gears were then calculated as:

$$
R i(y)=\frac{\operatorname{CPUEi}(y)}{\overline{C P U E i}(y 1, y 2)}
$$

The sum of the yields of gears for which effort is known was estimated using equation 4 :

$$
Y S(y)=\sum_{i=1}^{n} Y i(y)
$$

Finally the Weighted catch per unit effort (cpue or $R$ ) for quarter $y$ was calculated using $R i, Y i$ and $Y S$ with the equation: 


$$
\text { cpue or } R(y)=\sum_{i=1}^{n}\left(R i(y) * \frac{Y i(y)}{Y S(y)}\right)
$$

The Relative effort (Effort) for each quarter $y$ was also calculated using $Y S$ and cpue $(R)$ with the equation:

$$
\text { Relative effort or Effort }(E y)=\frac{Y S(y)}{R(y)}
$$

\section{Construction of the cpue Model and Effort Model}

Generalized Additive Models (GAM) was performed with mgev (Wood and Augustin, 2002) package in R (3.5.2). Auto correlation function (ACF) was performed to identify suitable lags of environmental variables. GAM was then used to develop models of the cрue and lagged climatic variables for IOS along the Kerala coast.

The use of GAM in environmental studies is helpful, especially when the relation between the response and the explanatory variable is non-linear and not well understood in advance. Moreover GAM models have been demonstrated to be powerful tools for predicting future fish distributions (Rutterford et al., 2015). The GAMs are semi-parametric approaches that allow for the inclusion of distribution network of independent variables as a function of the response variable. The response variable is modelled by a sum of smooth functions of covariates. The general structure of GAM can be written as:

$$
\begin{aligned}
& g\left(E\left(Y_{i t}\right)\right)=\beta X_{i t}+\sum_{j=1}^{n} f_{j}\left(x_{i}\right) \\
& Y_{i t}=E\left(Y_{i t}\right)+\epsilon_{i t}
\end{aligned}
$$

Where $g$ is a link function, $Y$ denotes the response variable, the vector $\beta$ contains fixed parameters, $X_{i t}$ is a row of fixed effects matrix and $f_{j}$ are smoothing splines of the $\boldsymbol{n}$ explanatory covariates, $x_{i}$. The residual errors $\epsilon_{i t}$ are random Gaussian noise with mean 0 . To avoid overfitting, and integrate the optimal smoothing parameters Cross Validation (GCV) described by Golub, Heath, and Wahba (1979) was used, and degrees of freedom were manually estimated by trial and error method. The model was constructed in a stepwise manner and predictor variable subset selection was done by using the lowest Akaike Information Criterion (AIC) score (Greven and Kneib, 2009). GAM model was then developed for Effort for two RCP scenarios. Here also SST, Pr, SSC and SSS were considered as predictors and Relative fishing effort as response variables.

\section{Model selection, Validation and Prediction}

The candidate models were compared by means of AIC, R squared statistic and F-statistic. The adequacy of the models was confirmed by analysing the independent and random distribution of the residuals over time, homoscedasticity for error variance and normal distribution of errors. The best fit model was then selected. The cpue was considered as response variable and SST, SSC, SSS and Pr were treated as predictors in the models. The selected model, in which smoothing spline functions are used to model the cpue and the climatic variables, were:

$$
\begin{aligned}
& \text { cpue } \sim \mathrm{s}(\mathrm{SST})+\mathrm{s}(\mathrm{SSS})+\mathrm{s}(\mathrm{SSC})+\mathrm{s}(\mathrm{Pr}) \\
& \text { Effort } \sim \mathrm{s}(\mathrm{SST})+\mathrm{s}(\mathrm{Pr})+\mathrm{s}(\mathrm{SSC})+\mathrm{s}(\mathrm{SSS})
\end{aligned}
$$

The evaluation of model was done by cross-validation test Training data set was selected as the $80 \%$ total Actual data to build the model. Model validation was then done using a test data containing $20 \%$ of actual data and the results were compared.

Prediction was done using gam.predict function of $\mathrm{mgcv}$ package in $\mathrm{R}(3.5 .2)$. In order to assess the prediction performance of the models $80 \%$ of the data were used to evaluate offset between predicted values of the model and the original values. This was checked based on the root mean squared error (RMSE). The model with smaller RMSE has better predictive performance. The ACF (Auto Correlation Function) and PACF (Partial Auto Correlation function) were used to test the independent random distribution of the residuals of the models.

\section{Estimation of Future Catch}

The catch potential of Sardinella longiceps for 2020-2100 was estimated using the equation;

$$
Y S(y)=\text { Relative effort } E(y) * R(y)
$$

Where $y$ is the quarter of the year and $E(y)$ and $R(y)$ are predicted Effort and cpue respectively for corresponding quarters of the period 2020-2100.

\section{RESULTS}

The IOS along Kerala coast experienced large variations overtime. This is illustrated by increased catch after the introduction of Mechanized gears in the middle 1980s followed by a great reduction in the catch during the period 1992-1997 (54118-30607 tons). In the later years the catch again revived and reached peak in 2011 (322102.97 tons) and 2012 (399786.447 tons). Further reduction in catch is observed during the period 2012 to 2017 (126987.786 tons). The fluctuations in the fishery of IOS are shown in Figure 2.

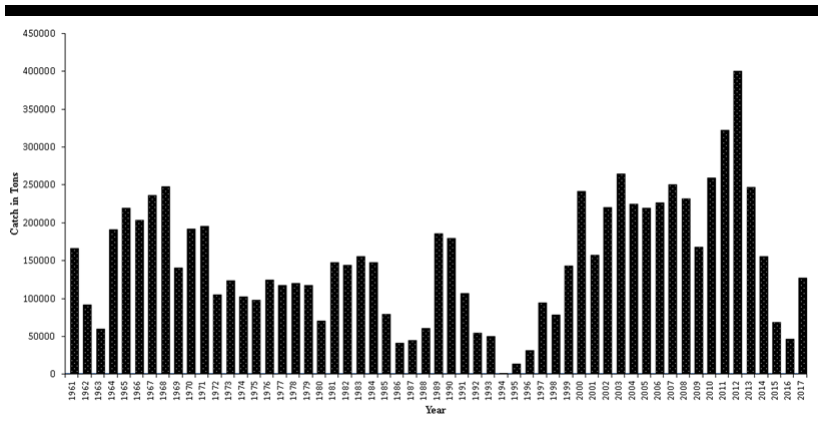

Figure 2. Catch of Indian oil sardine along Kerala coast during the period 1960-2016.

\section{Changes in the Environment}

The values of these oceanographic variables, SST, SSS, SSC and $\operatorname{Pr}$ of the study region have changed substantially since the 

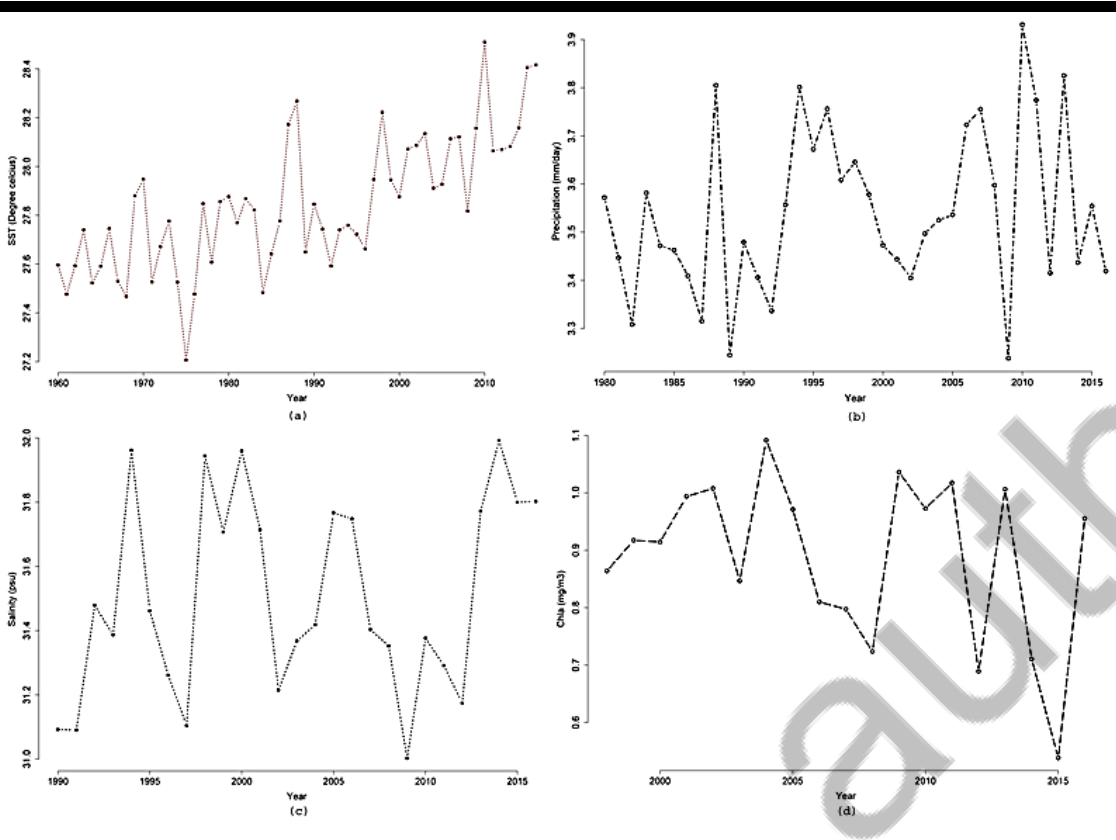

Figure 3. Environmental variables for historic period along Kerala coast - SST (a), Pr (b), SSS (c) and SSC (d).

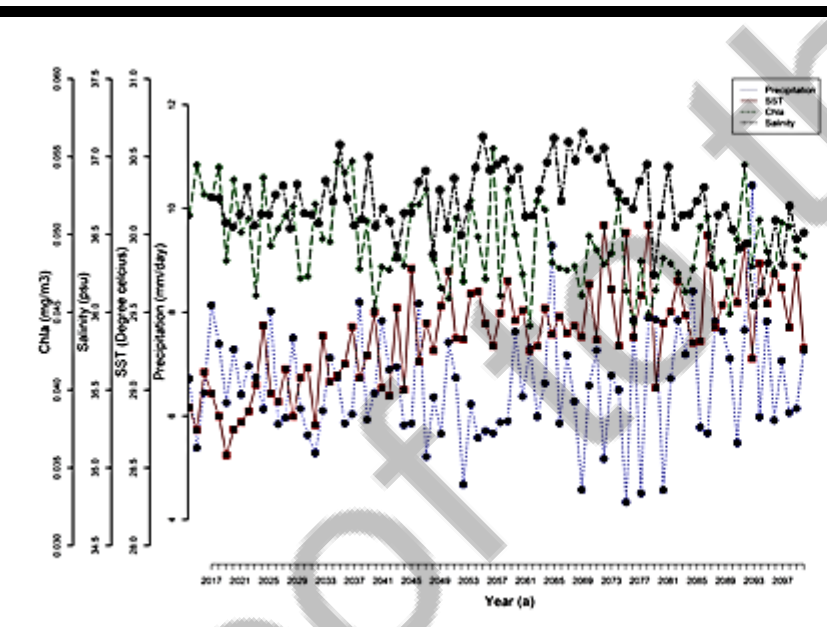

Figure 4. Trend of Average SST, Pr, SSS and SSC of the two climate change scenarios RCP 4.5 (a) and RCP 6.0 (b).

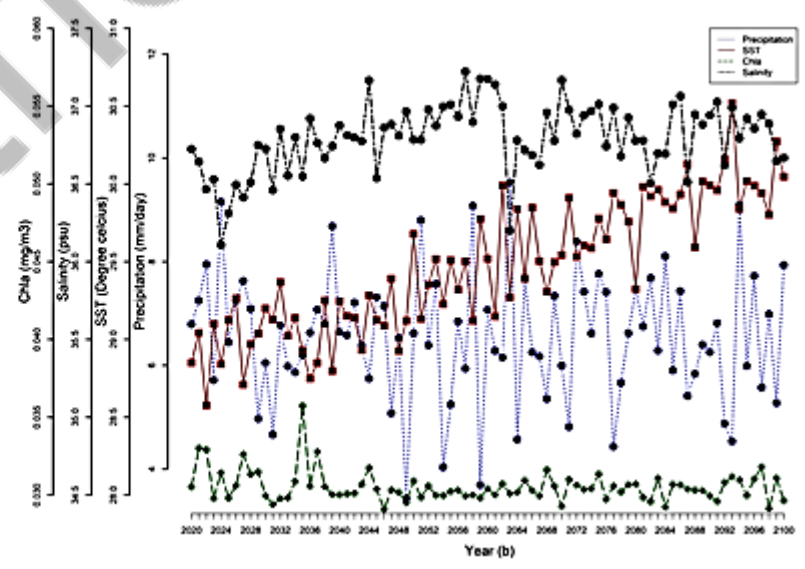

beginning of the $20^{\text {th }}$ century (Figure 3 ). Notably, the average SST has considerably increased since 1998 (Figure 3a). Average precipitation of the study area shows an increasing trend with more frequent peaks and fall (Figure 3b). The SSS has exhibited a steep increase in the years 1994, 98-'00, 2005-'06 and 2013'14 (Figure 3c). The SSC concentration shows a decreasing trend since 2004 (Figure 3d).

The expected future temporal variations in environmental variables under the two climate change scenarios RCP 4.5 and RCP 6.0, in the geographical area of interest are shown in (Figure 4). The trend of the change in SSS is increasing under RCP 4.5 (Figure 4a) whereas a decreasing trend of SSS is observed for RCP 6.0 (Figure 4b). Increasing trends in the SST, and a decreasing trend in Pr are expected over the next 80 years from 2020 to 2100 , and the increase is enhanced under the RCP 6.0 scenario (Figure $4 \mathrm{~b}$ ). The change in SSC shows a decreasing trend in RCP 6.0 (Figure 4b) when compared to RCP 4.5 scenario.

\section{Model Outputs}

The relationships of the cpue and fishing Effort of IOS with environmental variables were examined in the study. All predictor variables were found to be highly significant $(p<0.01)$ for both the cpue and Effort models, which suggest that all variables should be included in the models (Table 1). The variables were incorporated by stepwise selection method. The 
model in which all variables were included show greater $\mathrm{R}$ squared values, lower AIC, higher deviance and lower residual deviances. The summary of the models, deviance explained, AIC values and degrees of freedom are shown in Table 2 . The best model was determined by the model with the lowest AIC value. The removal of any predictors from the final model reduced the model performance, as shown in Table 2.

The PACF and ACF of the residuals of cpue and Effort model are shown in Figure 5. The results of the Model evaluation (1985-2016) are shown in Figure 6. The actual and predicted values compared to evaluate the model performance show that both cpue (Figure 6a) and Effort (Figure 6b) models performed well. When comparing the R square and AIC values of the two models it can be seen that Effort model performed better than the cpue model.

Table 1. Analysis of Deviance explained, AIC and significance of each parameter for cpue and Effort models.

\begin{tabular}{llcccl}
\hline Effort model df & $\mathrm{F}$ & $\begin{array}{c}\text { Deviance } \\
(\%)\end{array}$ & $\mathrm{AIC}$ & $\mathrm{p}$ value \\
\hline $\mathrm{s}(\mathrm{SSC})$ & 3.24 & 7.95 & 20.20 & 1513.05 & $0.000473^{* * *}$ \\
$\mathrm{~s}(\mathrm{SST})$ & 4.75 & 3.89 & 40.30 & 1490.96 & $1.95 \mathrm{e}-08^{* * *}$ \\
$\mathrm{~s}(\mathrm{Pr})$ & 11.52 & 8.89 & 62.90 & 1471.10 & $6.53 \mathrm{e}-12^{* * *}$ \\
$\mathrm{~s}(\mathrm{SSS})$ & 12.52 & 3.13 & 38.30 & 1508.77 & $0.00145^{* *}$ \\
cpue model & & & & & \\
$\mathrm{s}(\mathrm{SSC})$ & 3.08 & 3.43 & 10.90 & 276.72 & $0.00614^{* *}$ \\
$\mathrm{~s}(\mathrm{SST})$ & 12.81 & 4.06 & 44.60 & 262.93 & $0.000131^{* * *}$ \\
$\mathrm{~s}(\mathrm{Pr})$ & 5.96 & 0.89 & 15.60 & 278.68 & $0.0397^{*}$ \\
$\mathrm{~s}(\mathrm{SSS})$ & 3.09 & 1.13 & 17.00 & 271.72 & $0.000407^{* * *}$ \\
\hline
\end{tabular}

Table 2. Deviance explained, AIC, estimated degrees of freedom ( $d f$ ) and Adjusted R-square values of cpue and Effort models (obtained by sequentially adding each variable).

\begin{tabular}{lcccc}
\hline Model & $\mathrm{df}$ & $\begin{array}{c}\text { Deviance } \\
(\%)\end{array}$ & AIC & $\begin{array}{r}\text { Adjusted } \\
\mathrm{R} \text {-square }\end{array}$ \\
\hline cpue $\sim \mathrm{s}(\mathrm{SST})+\mathrm{s}(\mathrm{Pr})$ & 15.20 & 49.20 & 261.66 & 0.371 \\
cpue $\sim \mathrm{s}(\mathrm{SST})+\mathrm{s}(\mathrm{SSS})$ & 13.23 & 45.60 & 262.38 & 0.351 \\
cpue $\sim \mathrm{s}(\mathrm{SST})+\mathrm{s}(\mathrm{Pr})+$ & 15.38 & 49.50 & 261.50 & 0.374 \\
$\mathrm{~s}(\mathrm{SSS})$ & & & & \\
cpue $\sim \mathrm{s}(\mathrm{SST})+\mathrm{s}(\mathrm{Pr})+$ & 15.76 & 50.40 & 261.09 & 0.38 \\
$\mathrm{~s}(\mathrm{SSC})$ & & & & \\
cpue $\sim \mathrm{s}(\mathrm{SST})+\mathrm{s}(\mathrm{Pr})+$ & 19.48 & 55.40 & 261.00 & 0.403 \\
$\mathrm{~s}(\mathrm{SSS})+\mathrm{s}(\mathrm{SSC})$ & & & & \\
Effort $\sim \mathrm{s}(\mathrm{SST})+\mathrm{s}(\mathrm{Pr})$ & 11.63 & 63.10 & 1471.06 & 0.571 \\
Effort $\sim \mathrm{s}(\mathrm{SST})+\mathrm{s}(\mathrm{SSS})$ & 11.63 & 60.70 & 1471.06 & 0.514 \\
Effort $\sim \mathrm{s}(\mathrm{SST})+\mathrm{s}(\mathrm{Pr})+$ & 11.63 & 63.10 & 1471.06 & 0.571 \\
$\mathrm{~s}(\mathrm{SSS})$ & & & & \\
Effort $\sim \mathrm{s}(\mathrm{SST})+\mathrm{s}(\mathrm{Pr})+$ & 15.53 & 72.40 & 1458.44 & 0.655 \\
$\mathrm{~s}(\mathrm{SSC})$ & & & & \\
Effort $\sim \mathrm{s}(\mathrm{SST})+\mathrm{s}(\mathrm{Pr})+$ & 24.90 & 81.30 & 1450.16 & 0.719 \\
$\mathrm{~s}(\mathrm{SSS})+\mathrm{s}(\mathrm{SSC})$ & & & & \\
\hline
\end{tabular}

The effect of four environmental variables SST, Pr, SSC and SSS on the cpue (R) and Effort (E) are shown in Figure 7 and Figure 8 respectively. The $y$-axis values show the negative and positive effects of the environmental variables on cpue and Effort respectively. The results of the GAM model strongly suggest the influence of SST on cpue (R) of IOS. Increased cpue is observed at SST between $27^{\circ} \mathrm{C}$ and $29^{\circ} \mathrm{C}$. A further increase or decrease in SST negatively affects the cpue. The relation between SST and cpue is very wiggly which suggests the sensitiveness of the fish availability to SST (Figure 7a). A positive effect on the catch of IOS is observed at Pr below 4 $\mathrm{mm} /$ day, and a gradual declining trend is observed at $\operatorname{Pr}$ greater than $6 \mathrm{~mm} /$ day (Figure $7 \mathrm{~b}$ ). The cpue also shows a positive association with SSS. Higher cpue values are observed at SSS between 30.5 and $31.5 \mathrm{psu}$, and further increase or decrease in SSS is negatively associated with the cpue (Figure 7c). In contrast, SSC has a positive effect on the cpue of IOS. Increase in the cpue is observed with increasing SSC values (Figure 7d).

As revealed by GAM results high fishing Effort of IOS is expected for waters with temperatures between $27^{\circ} \mathrm{C}$ and $29^{\circ} \mathrm{C}$ (Figure 8a). The positive and negative effects are consistent with that of cpue. The effect of Pr is also similar to that of cpue (Figure $8 \mathrm{~b}$ ). The model indicates that the SSS exerts a negative effect on the Effort at values greater than 31.5 (Figure 8c). A positive effect of SSC on the Effort of IOS fishery is found at SSC concentrations above $1.0 \mathrm{mg} / \mathrm{m}^{3}$ (Figure $8 \mathrm{~d}$ ).

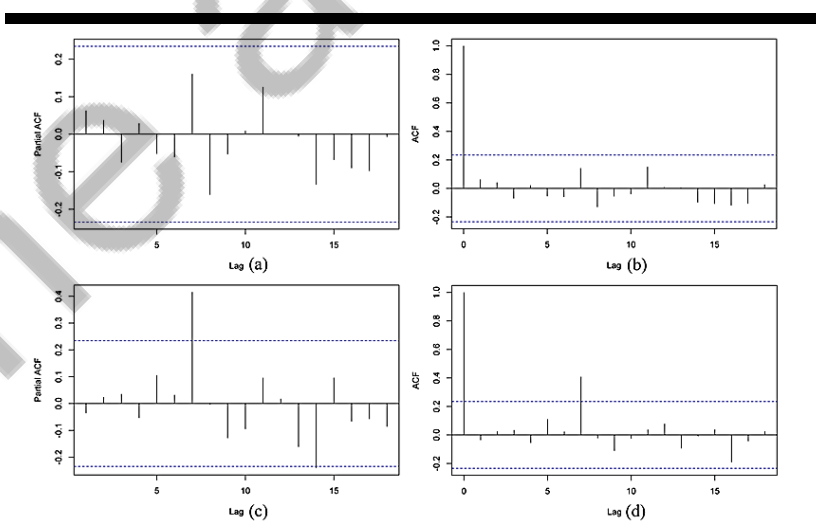

Figure 5. PACF and ACF of GAM model residuals cpue model (a, b) and Effort model (c, d).

Predicted cpue, Effort and Catch Potential of Oil sardine

The catch potential of IOS along Kerala coast for 2020-2100 was estimated using the predicted cpue and Effort values on quarterly basis. The GAM model prediction shows reduction in cpue under both RCP scenarios. The predicted cpue obtained for RCP 4.5 is higher when comapred to RCP 6.0. Though the cpue reduces in RCP 4.5, it first shows an increasing trend towards 2050 and then a graduall reduction towards 2100 (Figure 9a). The cpue of RCP 6.0 shows an increasing trend from 2020 to 2050 which then declines drastically towards 2100 (Figure 9b). The Effort predicted show an increase over time under both scenarios (Figure 10a and Figure 10b). Catch estimated (20202100) using the predicted cpue and Effort, for the two RCP scenarios show varying results. The predicted catch for RCP 4.5 show an increase towards 2050s which then gradually reduces towards 2100 (Figure 11). Compared to the catch of RCP 4.5, the predicted catch for RCP 6.0 after reaching a peak in 2050, it collapses drastically towards 2100 . 

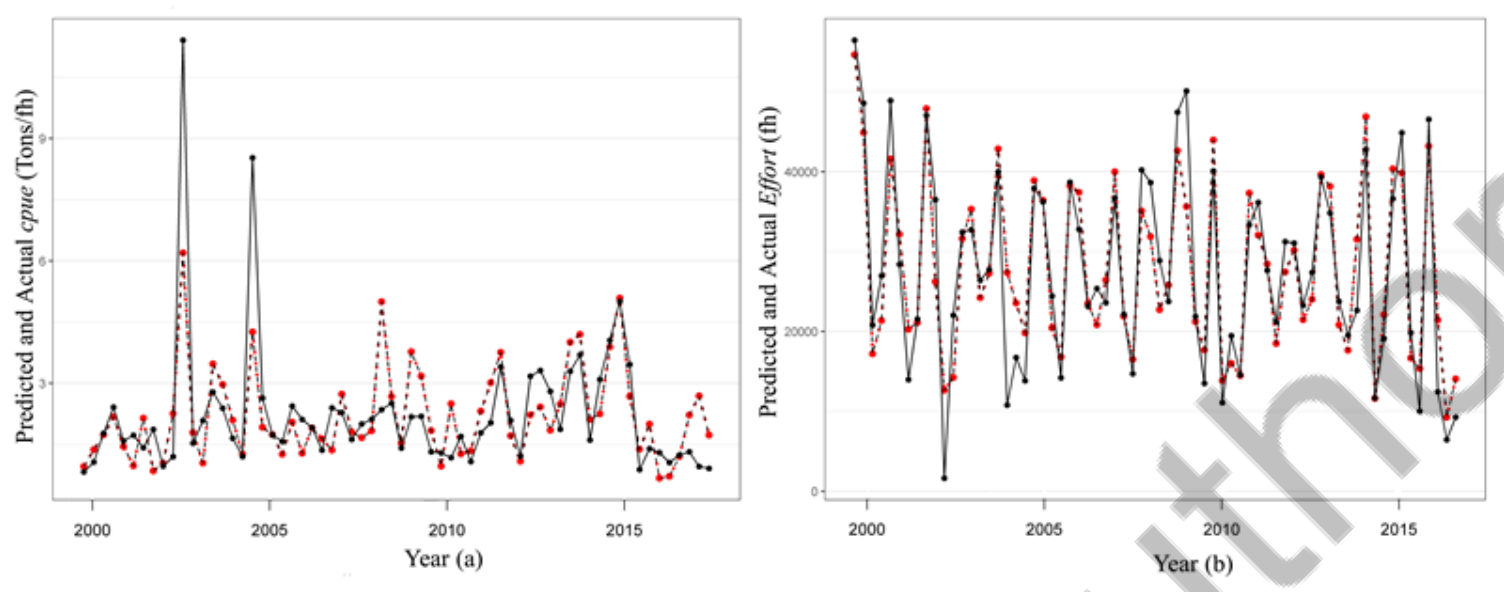

Figure 6. Model evaluations of cpue (a) and Effort (b) models.

The average catch of 2005-2015 period is used as a reference to compare with 5 year average of predicted catch for both climate change sceanrios. The observation shows that though the predicted yearly catch of IOS shows peaks in certain years, the average catch over 5 years first increases and then reduces in both climate change scenarios. In RCP 4.5 the 5 year average is expected to show an increase (50\%) followed by a decrease $(-150 \%)$. But the catch predicted for RCP 6.0 though shows an increase of $158 \%$ in 2050, it falls abruplty by 2100 (Figure 12).

\section{DISCUSSION}

The cpue and Effort based models are suitable for investigating abundance and distribution of the fishery of interest in relation to environmental variables (Yen et al., 2016). In this study, the relation between oceanographic variables and IOS over time could not foresee any method to predict exact 'cpue' or 'Effort' to assimilate changes in fish abundance and distribution. But the study could forecast yearly averages that can suggest trends in IOS abundance and distribution along the Kerala coast in the forecasted climate change scenarios.

IOS is an abundant coastal pelagic species, with high ecological and economic relevance that is often affected by inter-annual fluctuations and distributional shifts in the SW coast of India. The GAM model output indicates the sensitivity of IOS fishery to changes in SST, Pr, SSS and SSC. Each environmental variable is found to influence cpue of IOS in a sequence as $\mathrm{SST}>\mathrm{SSS}>\mathrm{SSC}>\mathrm{Pr}$ and Effort of IOS as $\mathrm{Pr}>$ SST $>$ SSC > SSS as shown in Table 1. Rutterford et al. (2015) has reported seasonal temperatures, salinity and likely covarying habitat variables to be major determinants of species distributions, and can be considered as good predictors of their distribution changes. Increase in SST influence the marine biological systems at organismal, population, community and ecosystem levels (Vivekanandan, 2013). The chlorophyll abundance is a vulnerable factor to oil sardine fishery as it determines the feeding ground and controls its recruitment (Piontkovski, Al-Oufi, and Al-Jufaili, 2014; Zaki et $a l .$, 2012). With the advent of satellite remote sensing techniques
(George, 2014), satellite aided information of chlorophyll abundance were utilized for unravelling the fluctuation in the abundance of IOS fishery (George et al., 2012; Menon et al., 2019). Rainfall (precipitation) data was utilized in previous studies to explain the inter-annual variability in IOS by Jayaprakash (2002). The results of the current study confirm that the changes in cpue and Effort are in relation with environmental variables. Long-term changes in climatic conditions are affecting the distribution and abundance of the population of IOS.
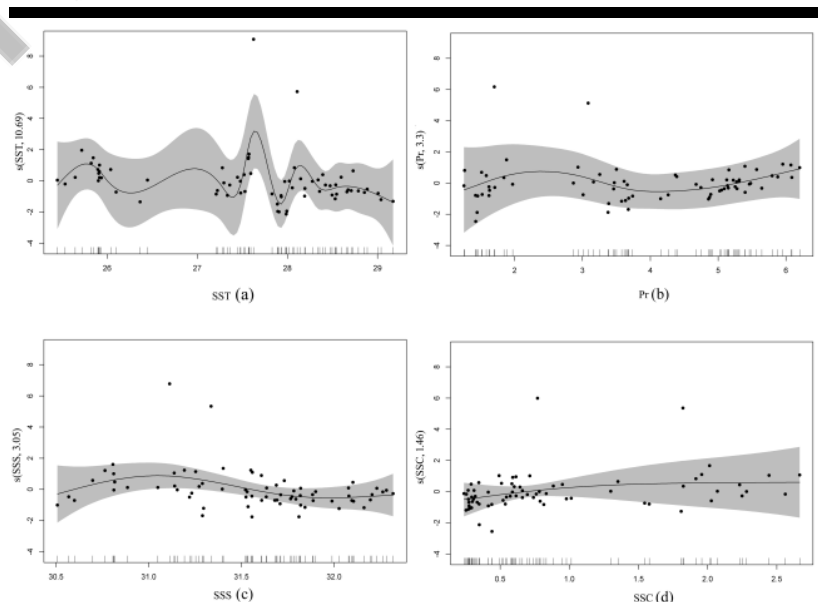

Figure 7. GAM model results of cpue model showing effect of SST (a), $\operatorname{Pr}(\mathrm{b})$, SSS (c) and SSC (d).

The сриe of RCP 4.5 and 6.0 predicted during 2020-2100 increases to the middle of the century followed by a reduction, which is more prominent in RCP 6.0 (Figure 9b). The Effort predicted for both climate change scenario showed increase over time. The reduced cpue compared to the increased Effort indicates a decline in the abundance and distribution of the fish in the region. The cpue and Effort for the total gears operating can also be used to predict the future catch. Hence by analyzing environmental variables and fishery data using GAM models, 
the approximate trend of future changes in the fishery of IOS along the Kerala coast is predicted for two climate change scenarios.

According to the GAM model prediction a large decline in the IOS fishery along Kerala coast with an intense recession after 2050 is expected for RCP 6.0 scenario. On the other hand the 4.5 scenario shows a gradual reduction in catch. The increasing effort which results in Fishing down the web leads to a great reduction in the prey population of small pelagic fishes such as IOS (Vivekanandan, Srinath, and Kuriakose, 2005).
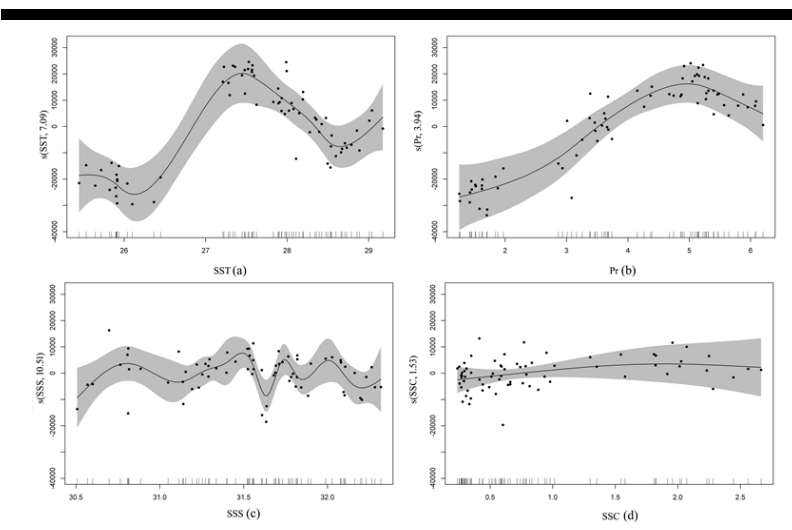

Figure 8. GAM model results of Effort model showing effect of SST (a), $\operatorname{Pr}(b)$, SSS (c) and SSC (d).

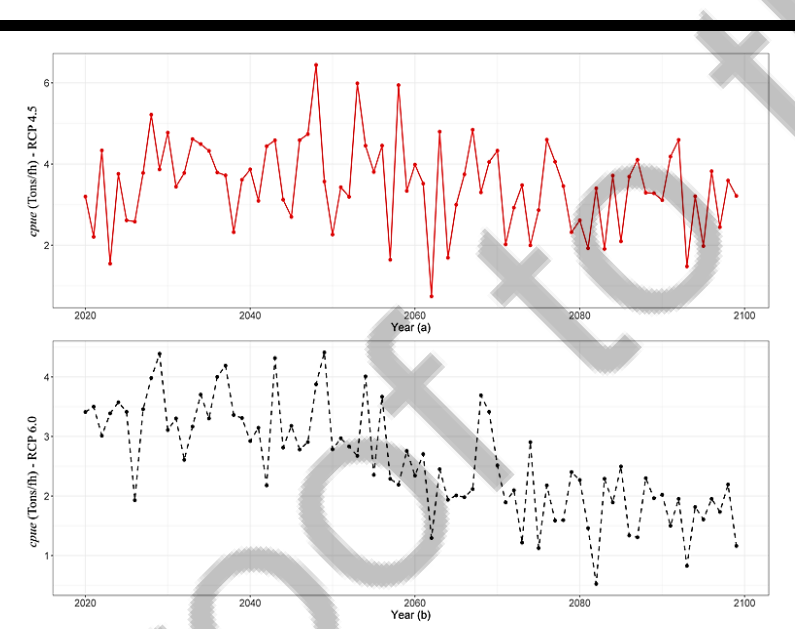

Figure 9. Predicted cpue for two RCP scenarios RCP 4.5 (a) and RCP 6.0 (b).

This in turn causes a surge in the biomass of small pelagic fish, which explains the initial increasing trend in the cpue and increasing catch of IOS with Effort till the middle of the century. Once the pelagic biomass surge has reached its maximum in the environment, there is a need for sustained production of chlorophyll to support the increasing grazing fish population. Adverse habitat conditions in our long term forecasts indicate the reduced availability of food items such as diatoms further leading to a competition among other peer fish species along with increased fishing pressure results in sudden collapse of the IOS.

Thus, the increase in SST $\left(>29^{\circ} \mathrm{C}\right)$, increase in $\operatorname{Pr}(>5$ $\mathrm{mm} /$ day) and lower SSC concentrations $\left(<0.03 \mathrm{mg} / \mathrm{m}^{3}\right)$ contribute to the collapse of the population in RCP 6.0 scenario. Studies have shown decline in the biomass of large predators and eventual increase in the population of small pelagic fishes (by 130\%) over the past century, which is not expected to be sustainable in the marine ecosystem conditions. A similar result forecasted in our model explains the reduction in catch beyond 2050 though the Effort increases further under both scenarios.

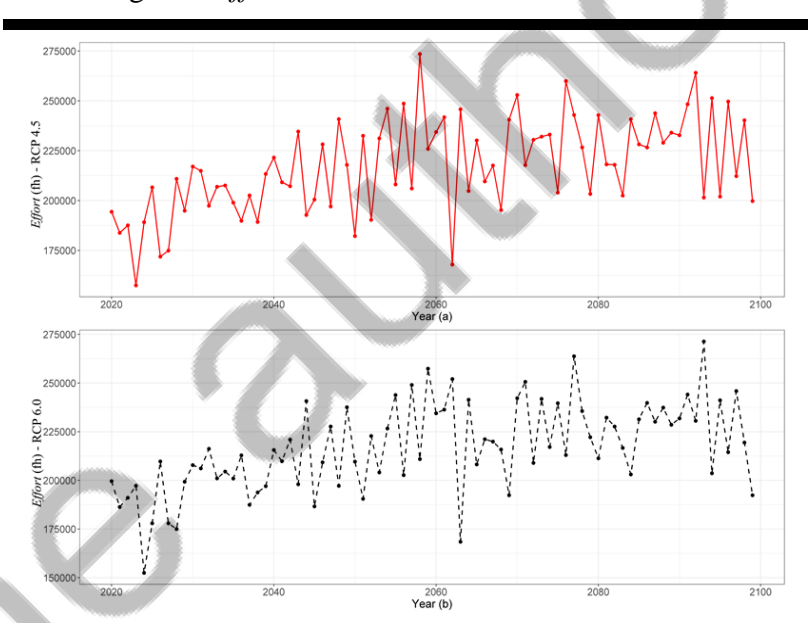

Figure 10. Predicted Effort for two RCP scenarios RCP 4.5 (a) and RCP 6.0 (b).

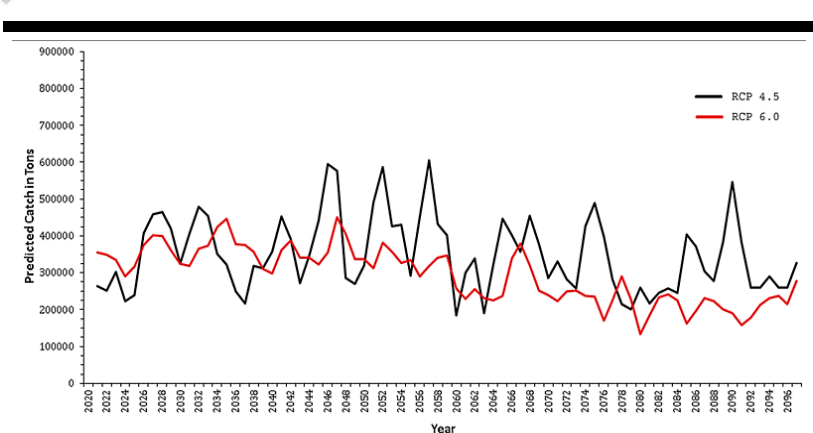

Figure 11. Predicted catch for two RCP scenarios RCP 4.5 and RCP 6.0.

The late recession of cpue (Figure 9a) and catch (Figure 11) predicted for IOS under RCP 4.5 might be due to a lower SST $\left(<29^{\circ} \mathrm{C}\right)$, decrease in $\operatorname{Pr}(<5 \mathrm{~mm} /$ day $)$ and increased SSC $(>0.05$ $\mathrm{mg} / \mathrm{m}^{3}$ ) after 2049 till 2070s. This may provide a comparatively more productive environment for the IOS population to survive in RCP 4.5 than a sudden collapse during corresponding periods under the RCP 6.0 scenario (Figure 11 and Figure 12). The results also reveals that increase in SST is one of the major factors that affects the changes in the distribution and abundance IOS. According to the current investigation the IOS along the Kerala coast is predicted to increase till 2050 which then reduces towards the end of 2100 under both climate change scenarios. This is supported by the findings of Cheung et al. (2010) which 
predicts maximum global catch potential in the year 2055, using models that linked geographic range of species with ocean conditions under low and high emission scenarios. IOS is a tropical fish whose tolerance range tends to be wider and the changes in temperature may not directly affect their survival, but can influence the life processes such as reproduction, spawning, food utilization and migration (Peck, 2011).

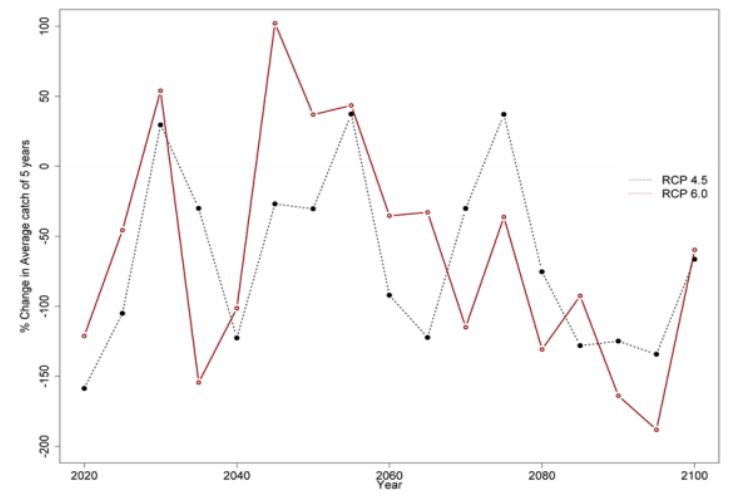

Figure 12. Percentage change of predicted 5 year Average catch of IOS compared to 10 year Average of 2005-2015.

The chances of migration of IOS is also supported by the studies of Vivekanandan, Rajagopalan, and Pillai (2008) which points out the emergence of the fish as a major fishery along SE coast and minor fishery along NE and NW coasts during 19502006, thereby reducing the percentage contribution of SW coast. Thus migration to favourable habitats can also be considered as a cause for reduction in the abundance of IOS after 2050 under RCP 6.0 and RCP 4.5. Since the ecological response of fishes to climate change are unknown, the predicted effect of decline in the fishery of IOS under the two RCP scenarios can also be expected to be influenced by their acclimation (Donelson, 2012; Stillman, 2003) and adaptation (Jennings, 2004) capacities.

IOS being a pelagic fish, is ecologically important as their large biomass is a crucial link in coastal food-webs, transferring the energy in plankton and small organisms to larger fishes, sea birds and marine mammals. It has also been stated earlier that Kerala contributes a great magnitude (up to 65\%) to the total catch of IOS of the country. Moreover, IOS has a significant role in fish food security in the state as it is considered as a low cost delicacy in adding to the poor men's protein (Shyam, Rahman, and Antony, 2015). The reduction in the abundance of IOS along Kerala coast not only cause loss in income but also leads to loss of fishing operations and employment days. Hence the reduced IOS catch in the fishery is expected to have ecological, economic and food security impacts. The decline in the IOS catch in both climate change scenarios points towards the alarming need for sustainable fisheries management practices.

\section{CONCLUSION}

The study elucidates the historic changes of oceanographic parameters and its trend along the Kerala coast. The future projections of the fishery of IOS suggest that if the fish fails to adapt or acclimatize to changing climatic conditions it might lead to reduction in the distribution and abundance of IOS along the Kerala coast, thereby affecting the fishery. Since IOS is a major marine fishery resource and mostly consumed fish species in Kerala state, its catch fluctuations in relation to climate change is of concern which points towards the alarming need of sustainable exploitation of the resources. The current investigation also shows the relevance of GAM models for predicting the future trend of fishery resources in relation to climate change. Inclusion of more predictor variables and subsequent refinement of the model can improve GAM model predictions to get more accurate forecasts for fisheries management.

\section{ACKNOWLEDGMENTS}

We greatly acknowledge the financial support received from the Indian Council of Agricultural Research through the Council monitored national research project 'National Innovations in Climate Resilient Agriculture' for carrying out the study.

\section{LITERATURE CITED}

Antony Raja, B.T., 1969. Indian Oil sardine. CMFRI Bulletin, 16, 1-142.

Brander, K.M., 2007. Global fish production and climate change. Proceedings of the National Academy of Sciences, 104 (50), 19709-19714.

Brierley, A.S. and Kingsford, M.J., 2009. Impacts of climate change on marine organisms and ecosystems. Current Biology, 19 (14), R602-R614.

Cheung, W.W.; Lam, V.W.; Sarmiento, J.L.; Kearney, K.; Watson, R.E.G.; Zeller, D., and Pauly, D., 2010. Largescale redistribution of maximum fisheries catch potential in the global ocean under climate change. Global Change Biology, 16 (1), 24-35.

Cooperative Ocean/Atmosphere Research Data Service (COARDS), National Oceanic and Atmospheric Administration Earth System Research Laboratory, 2018. https://www.esrl.noaa.gov/.

Coupled Model Intercomparison Project (CMIP5), Lawrence Livermore National Laboratory, 2017. https://st.llnl.gov/.

Cury, P.M.; Boyd, I.L.; Bonhommeau, S.; Anker-Nilssen, T.; Crawford, R.J.; Furness, R.W.; Mills, J.A.; Murphy, E.J.; Österblom, H.; Paleczny, M., and Piatt, J.F., 2011. Global seabird response to forage fish depletion-one-third for the birds. Science, 334 (6063), 1703-1706.

Donelson, J.M.; Munday, P.L.; McCormick, M.I., and Pitcher, C.R., 2012. Rapid transgenerational acclimation of a tropical reef fish to climate change. Nature Climate Change, 2 (1), p. 30.

George, G., 2014. Numerical modelling and satellite remote sensing as tools for research and management of marine fishery resources. In: Remote Sensing and Modeling, Cham, Switzerland: Springer, pp. 431-452.

George, G.; Meenakumari, B.; Raman, M.; Kumar, S.; Vethamony, P.; Babu, M.T., and Verlecar, X., 2012. Remotely sensed chlorophyll: a putative trophic link for explaining variability in Indian oil sardine stocks. Journal of Coastal Research, 28 (1A), 105-113. 
Golub, G.H.; Heath, M., and Wahba, G., 1979. Generalized cross-validation as a method for choosing a good ridge parameter. Technometrics, 21 (2), 215-223.

Greven, S. and Kneib, T., 2010. On the behaviour of marginal and conditional AIC in linear mixed models. Biometrika, 97 (4), 773-789.

Gulland, J.A., 1969. Manual of methods for fish stock assessment. Part I. Fish population analysis. FAO Manual of Fisheries Science, 4, 44 p.

International Comprehensive Ocean-Atmosphere Data set (ICOADS), National Oceanic \& Atmospheric Administration, 2018. http://icoads.noaa.gov/publications.html.

Jayaprakash, A.A., 2002. Long term trends in rainfall, sea level and solar periodicity: A case study for forecast of Malabar sole and Oil sardine fishery. Journal of the Marine Biological Association of India, 44 (1 \& 2), 163-175.

Jennings, S. and Blanchard, J.L., 2004. Fish abundance with no fishing: predictions based on macroecological theory. Journal of Animal Ecology, 73 (4), 632-642.

Krishnakumar, P.K. and Bhat, G.S., 2008. Seasonal and interannual variations of oceanographic conditions off Mangalore coast (Karnataka, India) in the Malabar upwelling system during 1995-2004 and their influences on the pelagic fishery. Fisheries Oceanography, 17 (1), 45-60.

Kumar, S.P.; Roshin, R.P.; Narvekar, J.; Kumar, P.D., and Vivekanandan, E., 2009. Response of the Arabian Sea to global warming and associated regional climate shift. Marine Environmental Research, 68 (5), 217-222.

Menon, N.N.; Sankar, S.; Smitha, A.; George, G.; Shalin, S.; Sathyendranath, S., and Platt, T., 2019. Satellite chlorophyll concentration as an aid to understanding the dynamics of Indian oil sardine in the south eastern Arabian Sea. Marine Ecology Progress Series, 1-11. doi: https://doi.org/10.3354/meps12806.

Miller, A.J. and Schneider, N., 2000. Interdecadal climate regime dynamics in the North Pacific Ocean: Theories, observations and ecosystem impacts. Progress in Oceanography, 47 (2-4), 355-379.

National Oceanic \& Atmospheric Administration, Geophysical Fluid Dynamics $\quad$ Laboratory, 2018. https://www.gfdl.noaa.gov/.

Peck, L.S., 2011. Organisms and responses to environmental change. Marine genomics, 4 (4), 237-243.

Perry, R.I., 2011. Potential impacts of climate change on marine wild capture fisheries: an update. The Journal of Agricultural Science, 149 (S1), 63-75.

Perry, A.L.; Low, P.J.; Ellis, J.R., and Reynolds, J.D., 2005. Climate change and distribution shifts in marine fishes. Science, 308 (5730), 1912-1915.

Piontkovski, S.A.; Al-Oufi, H.S., and Al-Jufaili, S., 2014. Seasonal and interannual changes of Indian oil sardine, Sardinella longiceps landings in the governorate of Muscat (the Sea of Oman). Marine Fisheries Review, 76, pp. 50-60.

Remya, R. and Vivekanandan, E., 2013. Adaptive capacity of the oil sardine Sardinella longiceps in the new distributional area with reference to food type. Climate Change and Environment, $107 \mathrm{p}$.

Rohit, P.; Sivadas, M.; Abdussamad, E.M.; Margaret MuthuRathinam, A.; Koya, K.P.; Ganga, U.; Ghosh, S.; Rajesh, K.M.; Mohammed Koya, K.; Chellappan, A., and Mini, K.G., 2018. Enigmatic Indian Oil Sardine: An Insight. CMFRI Special Publication No. 130, $156 \mathrm{p}$.

Rutterford, L.A.; Simpson, S.D.; Jennings, S.; Johnson, M.P.; Blanchard, J.L.; Schön, P.J.; Sims, D.W.; Tinker, J., and Genner, M.J., 2015. Future fish distributions constrained by depth in warming seas. Nature Climate Change, 5 (6), $569 \mathrm{p}$.

Sea-Data Analysis Center (SeaDAS), NASA Godard Space Flight Center, 2017. https://seadas.gsfc.nasa.gov/.

Shyam, S.S.; Rahman, M.R., and Antony, B., 2015. Sardine economy of Kerala: Paradigms and Perspectives. International Journal of Fisheries and Aquatic Studies, 2 (6), 351-356.

Smith, S.L. and Madhupratap, M., 2005. Mesozooplankton of the Arabian Sea: patterns influenced by seasons, upwelling, and oxygen concentrations. Progress in Oceanography, 65 (2-4), 214-239.

Stillman, J.H., 2003. Acclimation capacity underlies susceptibility to climate change. Science, 301(5629), $65 \mathrm{p}$.

Vivekanandan, E., 2013. Climate change: Challenging the sustainability of marine fisheries and ecosystems. Journal of Aquatic Biology and Fisheries, 1 (1\&2), 54-67.

Vivekanandan, E.; Rajagopalan, M., and Pillai, N.G.K., 2009. Recent trends in sea surface temperature and its impact on oil sardine. In: Global Climate Change and Indian Agriculture. Indian Council of Agricultural Research, New Delhi, pp. 89-92.

Vivekanandan, E.; Srinath, M., and Kuriakose, S., 2005. Fishing the marine food web along the Indian coast. Fisheries Research, 72 (2-3), 241-252.

Vivekanandan, E.; Srinath, M.; Pillai, V.N.; Immanuel, S., and Kurup, K.N., 2003. Trophic model of the coastal fisheries ecosystem of the southwest coast of India. In: Assessment, Management and Future Directions for Coastal Fisheries in Asian Countries. Silvestre, C.; Garces, L.; Stobutzki, I.; Ahmed, M.; Valmonte-Santos, RA; Luna, C.; LachicaAlino, L.; Munro, P.; Christensen, V., and Pauly, D. (eds.), World Fish Center Conference Proceedings, Penang, Vol. 67, pp. 281-298.

Wood, S.N. and Augustin, N.H., 2002. GAMs with integrated model selection using penalized regression splines and applications to environmental modelling. Ecological Modelling, 157 (2-3), 157-177.

Yen, K.W.; Su, N.J.; Teemari, T.; Lee, M.A., and Lu, H.J., 2016. Predicting the catch potential of Skipjack tuna in the western and central Pacific Ocean under different climate change scenarios. Journal of Marine Science and Technology, 24 (6), 1053-1062.

Zaki, S.; Jayabalan, N.; Al-Kiyumi, F.; Al-Kharusi, L., and AlHabsi, S., 2012. Maturation and spawning of the Indian oil sardine Sardinella longiceps Val. from the Sohar coast, Sultanate of Oman. Journal of the Marine Biological Association of India, 54 (1), 100-107. 